\title{
Results of Open Reduction and Internal Fixation in Calcaneal Fractures
}

\author{
(1) Metin Seyran ${ }^{1}$, (D) Murat Çakar² \\ ${ }^{1}$ Nizip State Hospital, Clinic of Orthopaedics and Traumatology, Gaziantep, Turkey \\ 2University of Health Sciences Turkey, Prof. Dr. Cemil Taşçığlu City Hospital, Clinic of Orthopaedics and Traumatology, Istanbul, Turkey
}

\section{Abstract}

Objective: We aimed to evaluate the clinical and functional outcomes of 45 patients who underwent open reduction and internal fixation for calcaneal fractures.

Methods: Sanders classification system was used to determine the fracture type. American Orthopaedic Foot and Ankle Society (AOFAS) hindfoot scale was used for clinical evaluation of patients. The patients were hospitalized with Jones bandage-like bandage or short leg splint. The patients were treated with ice, elevation, parenteral nonsteroidal anti-inflammatory drugs and thromboembolism prophylaxis. All of the patients were evaluated with wrinkle test at their visits. Those who were positive for wrinkle test were operated on a mean of 14.3 days (1-25). Four of the patients had minimally invasive surgery and 41 of them were operated with extended lateral intervention. The mean follow-up period was 25.8 months (8-56 months). After discharge, the patients were called for routine follow-up visits every 15 days, then monthly checks in the first 1.5 months, then every 3 months after the $6^{\text {th }}$ month and yearly after the 1 st year.

Results: Nine of 45 patients were female (20\%) and 36 were male (80\%). The mean age of the patients was 39.9 (21-60) years. Preoperatively, the mean Böhler angles were $3.6^{\circ}$ and the Gissane angles were 128.8. The mean AOFAS score was 83.9. According to the fracture type; this was 94.6 in patients with tongue fractures, 88 in type 2 patients, 82.8 in type 3 patients and 78.3 in type 4 patients.

Conclusion: As a result of this study good and satisfactory results can be obtained radiologically and functionally in Sanders type 2, type 3 and tongue type fractures. However, although we obtained radiologically good results in Sanders type 4 fractures, we did not achieve functional excellent results in any patients.

Keywords: Calcaneus, fracture, Sanders, open reduction, internal fixation

\section{INTRODUCTION}

Calcaneus is the most common fracture of the tarsal bones. 75\% of these fractures are intra-articular fractures. Etiologically, it is caused by high-energy injuries such as falls from high altitudes and traffic accidents, and other pathologies can be seen. The aim of the treatment is anatomical reduction of the subtalar, calcaneocuboid joints and to provide the length, width, height and valgus position of the calcaneus. In this study, we aimed to evaluate the results of the patients who underwent internal fixation in our clinic between 2010 and 2015 with current and literature information.

\section{METHODS}

In our study, 63 patients who underwent internal fixation after calceneus fracture between January 2010 and February 2015 Okmeydanı Training and Education Hospital Orthopedics and Traumatology Clinic were evaluated. Fifty fractures of 45 patients who could be reached or reached at their final controls were included in the study.

Nine of 45 patients were female (20\%) and 36 were male (80\%). The mean age of the patients was 39.9 (21-60) years. Seven of the patients were open fractures (15\%) and the rest were closed 
fractures $(85 \%)$. One of the fractures was caused by gunshot wounds and the others as a result of falling from a height. One patient had lateral malleolar fracture, two had tibial plateau fracture, two had distal radius fracture, three had vertebral fracture, two had tibial pilon fracture. Five (13.3\%) patients had bilateral involvement, 17 (34\%) had left side and 33 (66\%) had right side. Two patients had insulin dependent diabetes, one patient had cold urticaria, one patient had aortic valve insufficiency and one patient had epilepsy. All patients with bilateral fractures underwent open reduction and internal fixation.

Standard ankle AP and lateral radiographs were taken in all patients following the first emergency intervention. Computed tomography (CT) scans with axial, saggital and coronal sections were used for calcaneus fracture classification. Sanders classification system was used to determine the fracture type (1). Accordingly, 3 patients were tongue type, 10 patients were type 2, 27 patients were type 3 and 10 patients were type 4 . Distributions according to fracture type were shown in Figure 1. The patients were hospitalized with Jones bandage-like bandage or short leg splint. The patients were treated with ice application, elevation, parenteral nonsteroidal anti-inflammatory drugs and thromboembolism prophylaxis. All of the patients were evaluated with wrinkle test at their visits. Those who were positive for wrinkle test were operated on a mean of 14.3 days (between 1-25 days). Four of the patients had minimally invasive surgery and 41 of them were operated with extended lateral intervention.

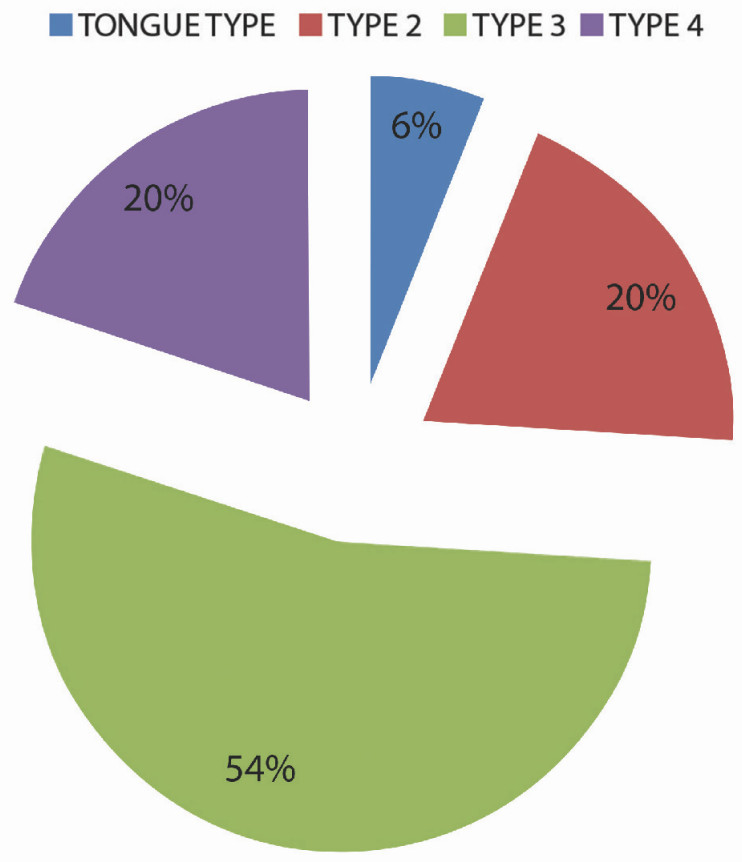

Figure 1. Sander classification of fractures
After the reduction was achieved, the bone cavity formed after elevation of the collapsed posterior facet was filled by cancellous graft in 40 patients. The fixation materials applied to the patients in this study were anatomic low-profile calcaneal plates with lockable headless screws.

After the first dressings, splint was removed and active motion was started with compressive bandage. Patients who had clinical and radiographic union at 6-8th weeks time and who had no problem of wound site were allowed to walk with full load.

\section{Statistical Analysis}

Frequency analysis was used as a descriptive statistical method. Statistically, only mean values were given in this study. Statistical analyzes were performed with using SPSS 19.0.

\section{RESULTS}

The mean follow-up period was 25.8 months (8-56 months). After discharge, the patients were called for routine follow-up visits every 15 days, then monthly checks in the first 1.5 months, then every 3 months after the $6^{\text {th }}$ month and yearly after the 1 st year. Patients with wound or nonunion problems were called to the controls more frequently. In addition to physical and radiological examinations, American Orthopaedic Foot and Ankle Society (AOFAS) posterior foot score, pain and clinical evaluations were performed.

The radiographs, tomography and postoperative radiographs of the patients were compared. Postoperative reduction success was evaluated quantitatively by evaluating Böhler and Gissane angles on lateral radiographs.

The mean AOFAS score was 83.9. Distributions of AOFAS scores according to the fracture type were seen in Table 1; this was 94.6 in patients with tongue fractures, 88 in Sanders type 2 patients, 82.8 in Sanders type 3 patients and 78.3 in Sanders type 4 patients. Postoperative Gissane angles of the patients were 123 in tongue type, 125.9 in Sanders type 2, 123.3 in Sanders type 3, and 115.1 in Sanders type 4; Böhler angles were found to be normal as; 34 in tongue type, 29.2 in Sanders type 2, 27.6 in Sanders type 3, and 26.5 in Sanders type 4. The mean

\begin{tabular}{|l|l|}
\hline Table 1. AOFAS hindfoot scores according to fracture type \\
\hline & AOFAS scores \\
\hline Tongue type & 94.6 \\
\hline Type 2 & 88 \\
\hline Type 3 & 82.8 \\
\hline Type 4 & 78.3 \\
\hline AOFAS: American Orthopaedic Foot and Ankle Society \\
\hline
\end{tabular}


preoperative and postoperative Gissane and Böhler angles of the patients were shown in Table 2.

Complications (24.4\%) developed in 11 patients. In Table 3 distrubution of complications could be seen. In 5 of these patients (11.1\%) wound site necrosis or opening was seen. Two of these 5 patients were treated with appropriate antibiotherapy and the other 2 patients (4.4\%) required implant removal. One of the patients whose implants were removed had insulin dependent diabetes and the other had epilepsy. Removal time after surgery was 8 months in diabetic patient and 12 months in epileptic patient. In 1 patient, debridement and primary closure was performed in the $6^{\text {th }}$ postoperative month because the necrosis area did not close. 1 patient developed pseudoarthrosis due to deep infection. Subtalar arthrodesis was performed and implants were removed. One patient required implant removal due to lateral compression of the implant. A patient with type $3 \mathrm{BC}$ fracture did not relieve the pain and underwent subtalar arthrodesis. During follow-up, the patient had no complaints. Sudeck atrophy was observed in 3 patients at 3 months postoperatively. Physical therapy and calcium phosphate-vitamin D treatment were started. After 3 months of treatment, complaints disappeared.

\section{DISCUSSION}

Increasing technological developments all over the world; the incidence of calcaneal fractures increases with the increase in occupational accidents and high speed automobile use.

It is more common in the male population as it is mostly seen after heavy work accidents. Some studies have shown that patients with calcaneal fractures are mostly seen in men aged 40 years (2-4). In our study, it was determined that $80 \%$

Table 2. Comparison of Gissane and Böhler angles according to fracture type

\begin{tabular}{|l|l|l|l|l|}
\hline \multirow{2}{*}{} & \multicolumn{2}{|l|}{ Pre-operative } & \multicolumn{2}{l|}{ Post-operative } \\
\cline { 2 - 5 } & Gissane & Böhler & Gissane & Böhler \\
\hline Tongue type & 121 & -43 & 123 & 34 \\
\hline Type 2 & 126.4 & 2.6 & 125.9 & 29.2 \\
\hline Type 3 & 132.2 & 7.2 & 123.3 & 27.6 \\
\hline Type 4 & 124.1 & 3.5 & 115.1 & 26.5 \\
\hline
\end{tabular}

Table 3. Complications after surgery

\begin{tabular}{|l|l|l|}
\hline Complication & Number of patients & $\%$ \\
\hline Wound site necrosis & 5 & 11.1 \\
\hline Sudeck atrophy & 3 & 6.6 \\
\hline Deep infection & 1 & 2.2 \\
\hline Compression of the implant & 1 & 2.2 \\
\hline Subtalar arthrodesis & 1 & 2.2 \\
\hline
\end{tabular}

of the patients were male and the mean age was 39.9 years in accordance with the literature.

Although the time to return to work with non-surgical treatment appears to be shorter, patients have been reported to have worse long-term outcomes (5). In our study, we found that the mean time to return to work was 5.5 (between 4-11 months) months in our patient group who underwent surgery.

Although treatment uncertainties remain for physicians at present, many orthopedists now use the Sanders classification system based on $\mathrm{CT}$, which is easily accessible and closely related to patient prognosis. According to this classification, nondisplaced intraarticular fractures (Sanders type 1) are treated conservatively. In Sanders type 2 and 3 fractures, if there are no contraindications, open reduction and internal fixation are recommended. There are different opinions in type 4 fractures. Primary arthrodesis, open reduction and internal fixation, conservative treatment and subsequent subtalar arthrodesis are the treatment modalities (1,5-9). Preoperative CT images were obtained in all patients included in this study and the patients were classified according to the Sanders classification system (1).

Sanders et al. (7) reported that anatomic reduction was necessary to achieve good and excellent results in a series of 120 patients with 29-month follow-up, but that anatomic reduction may not be accurate due to cartilage damage at the time of trauma. In addition, they stated that the surgeon who would perform calcaneal fracture surgery had a learning curve of 35-50 cases. They found good and excellent results in $73 \%$ of patients with type 2 fractures and $70 \%$ in patients with type 3 fractures. In this study, they emphasized that primary arthrodesis is necessary in type 4 fractures. When the surgery is decided, it is very important to decide which approach provides the most ideal vision. In the mid-1970s, when surgery became popular again in the treatment of calcaneal fractures, many invasive techniques such as medial, sustentacular, sinus tarsi, as well as lateral exten- sive approaches have been described (10-14). Minimally invasive techniques are impressive because they cause less damage to the soft tissue. However, reduction of joint compliance is considered indirect. Burdeaux (15), Stephenson (16), Essex Lopresti (17), Rammelt et al. (18) and Gavlik et al. (19) treated calcaneal fractures using a variety of minimally invasive techniques and recommended minimally invasive methods.

Today, many researchers have agreed on the extensile lateral approach, which is a notouch technique for intraarticular displaced calcaneal fractures $(7,10,11,13,14,20,21)$. This approach, known as the Kocher incision, was popularized by Palmer (22) in the 1940s. However, they could not obtain satisfactory results due to high infection rate and wound 
problems. Letornel modified the Palmer approach by removing the incision margins more posteriorly and inferiorly as a fullthickness skin flap. Thus, it caused less peroneal tendon damage, sural nerve lesion, calcaneofibular ligament damage and skin problem. This approach has been used in many large-scale studies $(7,10,11,13,20,23-26)$. In our study, we used extended lateral approach in 41 of 45 patients. We operated one patient in type $3 \mathrm{AB}$ class and three patients with tongue fractures with minimally invasive and percutaneous screwing.

However, when surgery is decided, its timing is crucial because massive edema makes surgery contraindicated $(27,28)$. Rammelt and Zwipp (6) proposed the wrinkle test for surgical timing. The general opinion of calcaneal fractures is that conservative treatment should be considered because of joint consolidation when the waiting period exceeds 3 weeks $(6,7,25,29)$. In our practice, we are in favor of postponing surgery until the patients' fracture test is positive. In our study, we found that the time from the operation to the postoperative period of our patients was 14.3 days $(1,30)$.

The general opinion for the postoperative period is to start early movement. Zwipp et al. (11) $(6,10,18)$ recommended movement to patients on the first postoperative day, while many authors recommended waiting for sutures until removal. There are also differences of opinion on the issue of weight bearing. Some authors suggested partial load on the patient's own shoes as soon as possible $(11,30)$, whereas Sanders recommended that the foot be kept in a neutral position to avoid crop contracture and that a weight bearing would be given after 12 weeks. In our study, we started compressing the bandage on the post-op day 2 when the patients were draining. All patients were given weight at $6^{\text {th }}$ and $8^{\text {th }}$ weeks.

Complications are a common problem in the treatment of calcaneal fractures. Superficial skin necrosis is the most common complication of operative treatment $(6,7,27,31,32)$. It can be seen in an average of $14 \%$ of cases after the standard extended lateral approach. $(2,6,13,32,33)$ In our study, complications occurred in 11 patients (24.4\%) after calcaneus surgery. Five of these patients (11.1\%) were wound necrosis or opening. Two of these 5 patients were treated with appropriate antibiotherapy and the other 2 patients (4.4\%) required implant removal. One of the patients whose implants were removed had insulin dependent diabetes and the other had epilepsy. In 1 patient, debridement and primary closure was performed in the $6^{\text {th }}$ postoperative month because the necrosis area did not close.

Due to the popularity of the extended lateral approach, the most common cutaneous sural nerve lesion was not seen in any of our patients $(7,34,35)$. Sudeck atrophy was observed in 3 patients at 3 months postoperatively. Physical therapy and calcium phosphate-vitamin D treatment were started. After 3 months of treatment, complaints disappeared. Deep vein thrombosis was not seen in any patient.

Various scales are used in the clinical evaluation of patients after calcaneus fracture. Similar scales with similar features are Maryland foot ratings, Creighton-Nabraska foot ratings, and AOFAS hind foot scale (36). In his study of 120 patients, Sanders (8) used the Maryland foot score and stated that anatomic reduction is essential to achieve good results, but that cartilage damage during trauma cannot be guaranteed. In our study consisting of 45 patients, AOFAS hindfoot evaluation scale was implemented. Accordingly, we achieved excellent results in $23.5 \%$, good results in $50 \%$, moderate results in $14.7 \%$ and poor results in $11.7 \%$. In our study, we think that even in fractures in which we achieved anatomic reduction in type 3 and type 4 fractures, cartilage destruction and the large number of fracture fragments in the posterior facet was the reason for low results. In line with this idea, we found that the Sanders classification gives information about the prognosis in direct proportion with the thesis.

\section{CONCLUSION}

Calcaneal fractures constitute $2 \%$ of all fractures and $60 \%$ of tarsal bone fractures. It can cause socioeconomic problems both for the patient and the public in patients who cannot be treated appropriately because it occurs in active individuals around the age of 40 years. Nowadays, the general treatment principle of displaced intra-articular calcaneal fractures is anatomic reduction and early onset of motion due to the development of both diagnostic and treatment alternatives. The surgeon's experience in the treatment of calcaneal fractures, factors such as chronic diseases of the patient and the damage of the cartilage at the time of injury may affect the success of the treatment. In addition, the increase in the population in accordance with the Sanders classification adversely affects the prognosis. Therefore, the patient should be informed that a successful surgery cannot always have successful results.

\section{Ethics}

Ethics Committee Approval: Okmeydanı Training and Reserach Hospital Ethic Comittee approved the study (28.04.2015/318).

Informed Consent: All participants give informed consent for the participation in this study.

Peer-review: Externally and internally peer-reviewed.

\section{Authorship Contributions}

Surgical and Medical Practices: M.S., M.Ç., Concept: M.Ç., M.S., Design: M.S., Data Collection or Processing: M.S., Analysis or Interpretation: M.S., Literature Search: M.S., Writing: M.S., M.C. 
Conflict of Interest: No conflict of interest was declared by the authors.

Financial Disclosure: The authors declared that this study received no financial support

\section{REFERENCES}

1. Sanders R, Fortin P, DiPasquale T, Walling A. Operative teratment in 120 displaced intraarticular calcaneal fractures. Results using a prognostic computed tomography scan classification. Clin Orthop Relat Res 1993;290:87-95.

2. Murphy GA. Fractures and dislocations of foot. In: Campbell's Operative Orthopaedics, Volume Four, 10 $10^{\text {th }}$ edition. Mosby, Philadelphia; 2003. pp. 4231-47.

3. Sanders R, Hansen ST, McReynolds IS. Trauma to the calcaneus and its tendon. In: Jahss MH, editor. Disorders of the Foot and Ankle. Medical and Surgical Management. Philadelphia, London, Toronto, Mexico City, Rio de Jenario, Sydney, Tokyo: W.B. Saunders Com.

4. Sanders R. Displaced intra-articular fractures of the calcaneus. J Bone Joint Surg Am 2000;82:225-50.

5. Coghlin MJ. Calcaneal fractures in the industrial patient. Foot and Ankle Int 2000;21:896- 905.

6. Rammelt S, Zwipp H. Calcaneal fractures: facts, controversies and recent developments. Injury 2004;35:443-61.

7. Sanders R. Displaced intra-articular fractures of the calcaneus. J Bone Joint Surg Am 2000;82225-50.

8. Thordarson DB. Foot and ankle trauma. In: Thordarson DB, editor. Foot Ankle (Orthopedic Surgery Essentials). Lippincot Williams \& Wilkins, Philadelphia; 2004. pp. 288-319.

9. Clare MP. Calcaneal fractures. In: Pinzur MS, editor. Orthopedic Knowledge Update: Foot and Ankle 4, American Academy of Orthopaedic Surgeons; 2008. pp. 75-94.

10. Letournel E. Open teratment of acute calcaneal fractures. Clin Orthop Relat Res 1993;290:60-7.

11. Zwipp H, Tscherne H, Thermann H, Weber T. Osteosynthesis of displaced intraarticular fractures of the calcaneus. Results in 123 cases. Clin Orthop Relat Res 1993;290:76-86.

12. Crosby LA, Fitzgibbons TC. Open reduction and internal fixation of type II intra-articular calcaneus fractures. Foot Ankle Int 1996;17:253-8.

13. Bezes H, Massart P, Delvaux D, Fourquet JP, Tazi F. The operative treatment of intraarticular calcaneal fractures. Indications, technique, and results in 257 cases. Clin Orthop 1993;290:55-9.

14. Thordarson DB, Latteier M. Open reduction and internal fixation of calcaneal fractures with a low profile titanium calcaneal perimeter plate. Foot Ankle Int 2003;24:217-21.

15. Burdeaux BD Jr. Fractures of the calcaneus: open reduction and internal fixation from the medial side, a 21-year prospective study. Foot Ankle Int 1997;18:685-92.

16. Stephenson JR. Surgical treatment of displaced intraarticular fractures of the calcaneus. A combined lateral and medial approach. Clin Orthop Relat Res 1993;290:68-75.

17. Essex Lopresti P. The mechanism, reduction technique, and results in fractures of the os calcis. Br J Surg 1952;39:395-419.
18. Rammelt S, Gavlik JM, Barthel S, Zwipp H. The value of subtalar arthroscopy in the management of intra-articular calcaneus fractures. Foot Ankle Int 2002;23:906-16.

19. Gavlik JM, Rammelt S, Zwipp H. Percutaneous, arthroscopically-assisted osteosynthesis of calcaneus fractures. Arch Orthop Trauma Surg 2002;122:424-8.

20. Crosby LA, Fitzgibbons TC. intraarticular calcaneal fractures results of closed treatment. Clin Orthop 1993;290:47-54.

21. Myerson M, Quill-Ge Jr. Late complications of the fractures of the calcaneus. J Bone Joint Surg Am 1993;75:331-41.

22. Howard JL, Buckley R, McCormack R, Pate G, Leighton R, Petrie D, et al. Complications following management of displaced intra-articular calcaneal fractures: A prospective randomized trial comparing open reduction internal fixation with nonoperative management. J Orthop Trauma 2003;17:241-9.

23. Crosby F, Fitzgibbons T. Computerized tomography scanning of acute intra- articular fractures of the calcaneus. A new classification system. J Bone Joint Surg Am 1990;72:852-9.

24. Leung KS, Yuen KM, Chan WS. Operative treatment of displaced intraarticular fractures of the calcaneum. J Bone Joint Surg Br 1993:196-201.

25. Buckley R, Tough S, McCormack R, Pate G, Leighton R, Petrie D, et al. Operative compared with nonoperative treatment of displaced intraarticular calcaneal fractures: A prospective, ramdomized, controlled multicenter trial. J Bone Joint Surg Am 2002;84:1733-44.

26. Buckley RE, Meek RN. Comparison of open versus closed reduction of intraarticular calcaneal fractures: a matched cohort in workmen. J Orthop Trauma 1992;6:216-22.

27. Abidi NA, Dhawan S, Gruen GS, Vogt MT, Conti SF. Wound healing risk factors after open reduction and internal fixation of calcaneal fractures. Foot Ankle Int 1998;19:856-61.

28. Folk JW, Star AJ, Early JS. Early wound complications of operative treatment of calcaneus fractures: analysis of 190 fractures. J Orthop Trauma 1999;13:369-72.

29. Thordarson DB, Krieger LE. Operative vs. nonoperative treatment of intra-articular fractures of the calcaneus: a prospective randomized trial. Foot Ankle Int 1996;17:2-9.

30. Cotton FJ, Henderson FF. Results of fractures of the os calcis. Am J Orthop Surg 1916;14:290-8.

31. Levin LS, Nunley JA. The management of soft-tissue problems associated with calcaneal fractures. Clin Orthop Relat Res 1993;290:151-6.

32. Benirschke SK, Sangeorzan BJ. Extensive intraarticular fractures os the foot. Surgical management of the calcaneal fractures. Clin Orthop Relat Res 1993;292:128-34

33. James ET, Hunter GA. The dilemma of painful old os calcis fractures. Clin Orthop Relat Res 1983:112-5.

34. Harvey EJ, Grujic L, Early JS, Benirschke SK, Sangeorzan BJ. Morbidity associated with ORIF of intra- articular calcaneus fractures using the lateral approach. Foot Ankle Int 2001;22:868-73.

35. Paley D, Hall H. Calcaneal fracture controversies: can we put humpty dumpty together again? Orthop Clin North Am 1989;20:665-77.

36. Kitaoka HB, Schaap EJ, Chao EY, An KN. Displaced intra-articular fractures of the calcaneus treated nonoperatively. Clinical results and analysis of motion and ground- reaction and temporal forces. J Bone Joint Surg Am 1994;76:1531-40. 